\title{
Hybridization drives genetic erosion in sympatric desert fishes of western North America
}

\author{
Tyler K. Chafin ${ }^{1} \cdot$ Marlis R. Douglas ${ }^{1} \cdot$ Bradley T. Martin ${ }^{1} \cdot$ Michael E. Douglas $^{1}$
}

Received: 29 May 2019 / Revised: 24 July 2019 / Accepted: 30 July 2019 / Published online: 20 August 2019

(c) The Author(s), under exclusive licence to The Genetics Society 2019

\begin{abstract}
Many species have evolved or currently coexist in sympatry due to differential adaptation in a heterogeneous environment. However, anthropogenic habitat modifications can either disrupt reproductive barriers or obscure environmental conditions which underlie fitness gradients. In this study, we evaluated the potential for an anthropogenically-mediated shift in reproductive boundaries that separate two historically sympatric fish species (Gila cypha and G. robusta) endemic to the Colorado River Basin using ddRAD sequencing of 368 individuals. We first examined the integrity of reproductive isolation while in sympatry and allopatry, then characterized hybrid ancestries using genealogical assignment tests. We tested for localized erosion of reproductive isolation by comparing site-wise genomic clines against global patterns and identified a breakdown in the drainage-wide pattern of selection against interspecific heterozygotes. This, in turn, allowed for the formation of a hybrid swarm in one tributary, and asymmetric introgression where species co-occur. We also detected a weak but significant relationship between genetic purity and degree of consumptive water removal, suggesting a role for anthropogenic habitat modifications in undermining species boundaries or expanding historically limited introgression. In addition, results from basin-wide genomic clines suggested that hybrids and parental forms are adaptively nonequivalent. If so, then a failure to manage for hybridization will exacerbate the long-term extinction risk in parental populations. These results reinforce the role of anthropogenic habitat modification in promoting interspecific introgression in sympatric species by relaxing divergent selection. This, in turn, underscores a broader role for hybridization in decreasing global biodiversity within rapidly deteriorating environments.
\end{abstract}

\section{Introduction}

Many natural populations respond to anthropogenic change by either shifting geographic distributions or adjusting life histories so as to "track" optimal conditions (Hoffmann and Sgrò 2011; Pecl et al. 2017). However, the ability of organisms to track changing environments is conditioned upon the rate of environmental change (Lindsey et al. 2013) and the rate at which adaptive machinery can act (Orr and Unckless 2014). This evolutionary caveat creates an

Supplementary information The online version of this article (https:// doi.org/10.1038/s41437-019-0259-2) contains supplementary material, which is available to authorized users.

Tyler K. Chafin

tkchafin@uark.edu

1 Department of Biological Sciences, University of Arkansas, Fayetteville, AR 72701, USA incentive for hybridization, in that recombinant genotypes might more rapidly establish in a dynamic adaptive landscape (Klonner et al. 2017). Widespread hybridization thus may provide an effective mechanism of population persistence in changing or novel conditions (Pease et al. 2016; Meier et al. 2017). Introgressed alleles that are beneficial under novel conditions can then be driven to fixation by the combined action of recombination and selection (Arnold and Martin 2010).

However, the relationship between hybridization and extinction is not well established under contemporary timescales. On one hand, hybrid lineages might facilitate adaptation by providing access to a greater pool of genetic variation (Dittrich-Reed and Fitzpatrick 2013; Schumer et al. 2018), whereas on the other, diversity might diminish as species boundaries dissolve (Buerkle et al. 2003; Kearns et al. 2018). Often, results are a combination of the above. Introgressed genotypes may initially compensate for erratic conditions and facilitate population persistence in the near term, but with lineages eventually merging if environmental 
change is prolonged (Seehausen et al. 2008). This presents an obvious paradox for conservation efforts, in that the permeability of species boundaries may be seen as promoting both persistence and extinction.

Hybridization also represents a legacy issue for conservation policy (Allendorf et al. 2001), due primarily to its conflict with a species-centric management paradigm (Fitzpatrick et al. 2015; Hamilton and Miller 2016). Although the reticulate nature of speciation has become a contemporary research focus (e.g., Mallet et al. 2016), it has yet to gain consensus among managers (VonHoldt et al. 2018). This unanimity is required to understand the manner by which anthropogenic modifications disrupt species boundaries (Grabenstein and Taylor 2018; Ryan et al. 2018). However, predicting the outcome of hybridization in a changing environment requires an understanding of both the temporal and spatial stability of the mechanisms (e.g., intrinsic and extrinsic) that are responsible for maintaining species boundaries. In this sense, consistent patterns can often be obscured by local context (e.g., individual behaviors, population demographics; Klein et al. 2017). Hence, there remains a need to quantify the manner by which species boundaries in diverse taxa respond to rapid environmental change. We applied these perspectives to endemic, large-bodied and long-lived minnows that exist within the Colorado River, one of the most impacted riverine ecosystems of the Anthropocene. Because of the pervasive human impacts therein, the Colorado River provides a natural laboratory within which to examine the stability of species undergoing rapid, anthropogenically-induced environmental change.

\section{Hybridization in Gila}

Hybridization has long been recognized as an evolutionary process in fishes (Hubbs 1955), and as such, has been hypothesized as a mechanism for native fish diversification in western North America (e.g., DeMarais et al. 1992). An inseparable link also exists between fishes and their environment, such that opportunities for migration or hybridization can be substantially influenced by characteristics of the riverscape (Hopken et al. 2013; Thomaz et al. 2016). The instability produced by modified flows may compromise boundaries between historically coexisting species, or provide ecological opportunities within which hybrid lineages might capitalize (Dowling and Secor 1997). The fact that habitats in western North America have a dynamic history including tectonism and progressive aridity also provides one potential causative factor for introgressive hybridization (e.g., Mandeville et al. 2017; Bangs et al. 2018). However, more contemporary anthropogenic modifications are also prominent and widespread, most apparent in the form of water acquisition and retention (Cayan et al. 2010). As a result, niche gradients that historically segregated species are now seriously perturbed. This, in turn, can promote hybridization by effectively removing selection against hybrid phenotypes, and by disrupting the phenology and reproductive cues that discourage heterospecific mating (Grabenstein and Taylor 2018).

We applied these perspectives to three species of conservation concern endemic to the Colorado River Basin: Humpback chub [Gila cypha $($ IUCN status $=$ Endangered $)$, Roundtail chub [G. robusta (Near Threatened)], and Bonytail [G. elegans (Critically Endangered)]. All are hypothesized as exhibiting various levels of historic hybridization, with contemporary populations shaped by geologic processes and anthropogenic interventions. Gila cypha and G. robusta, display not only morphological intergradation (McElroy and Douglas 1995) but also taxonomic ambiguity (Douglas et al. 1989) and cannot be distinguished on the basis of mitochondrial (mt)DNA (Douglas and Douglas 2007; Dowling and DeMarais 1993), despite numerous lines of evidence supporting evolutionary independence [genetic structuring in nuclear markers (microsatellites: Douglas and Douglas 2007); discrete persistence in the fossil record (e.g., Uyeno and Miller 1963, 1965); pre-mating isolation in the form of exclusive reproductive ecology and phenology (Kaeding et al. 1990); and divergent phenotypic evolution (Smith et al. 1979; Valdez et al. 1990; Portz and Tyus 2004)]. Also, McElroy and Douglas (1995) and Douglas et al. (1998) found clear species-level differentiation in discriminant and geometric morphometric space, respectively, while the former also reported species-intermediacy at two sympatric localities (Desolation and Cataract canyons).

A likely explanation for this mosaic pattern would invoke historic separation followed by hybridization. We examine this possibility herein and framed our results within the context of change both on geologic and contemporary timescales.

\section{Methods}

\section{Sampling}

Fin tissue was non-lethally sampled from 368 specimens across three native Gila of the Colorado River Basin ( $G$. cypha, G. elegans, and G. robusta; Table 1), collected primarily by state/federal agencies between 1997 and 2017 (see "Acknowledgements"). One location, at the San Rafael River (hereafter RSRR), was sampled both in 2009 and 2017. Given the conservation status of these fishes, we minimized impacts on already-stressed populations by opportunistic sampling, which took advantage of monitoring activities by agencies.

Gila cypha is constrained within five known aggregates associated with specific geomorphic features: Black Rocks, 
Table 1 Sampling locations for Gila robusta, $G$. cypha, and $G$. elegans

\begin{tabular}{|c|c|c|c|c|}
\hline Site & Major drainage & Location & County, State & $N$ \\
\hline \multicolumn{5}{|l|}{ Gila robusta } \\
\hline *RBKR & Colorado & Black Rocks Canyon & Mesa, CO & 11 \\
\hline *RDES & Green & Desolation Canyon & Uintah, UT & 23 \\
\hline RC15 & Colorado & 15-mile reach & Mesa, CO & 10 \\
\hline RECC & Little Colorado & East Clear Creek & Coconino, AZ & 16 \\
\hline RMCO & San Juan & Mancos River & Montezuma, CO & 10 \\
\hline RMGR & Green & Middle Green R. tributaries & Sweetwater, WY & 24 \\
\hline RNJA & San Juan & Navajo R. & Rio Arriba, NM & 10 \\
\hline RLSR & Yampa & Little Snake R. tributaries & Carbon, WY & 31 \\
\hline RLYC & Yampa & Little Yampa Canyon & Moffat, CO & 11 \\
\hline RSRR & Green & San Rafael R. & Emery, UT & 23 \\
\hline RUGR & Green & Upper Green R. tributaries & Sublette, WY & 16 \\
\hline RWRW & White & White R. mainstem near Weaver Cn. & Uintah, UT & 15 \\
\hline *RWWC & Colorado & Colorado mainstem near Westwater $\mathrm{Cn}$. & Grand, UT & 11 \\
\hline *RYAM & Yampa & Yampa R. mainstem & Moffat, $\mathrm{CO}$ & 15 \\
\hline \multicolumn{5}{|l|}{ Gila cypha } \\
\hline *HBKR & Colorado & Black Rocks Canyon & Mesa, CO & 18 \\
\hline *HDES & Green & Desolation Canyon & Uintah, UT & 24 \\
\hline HGCN & Colorado & Grand Canyon & Coconino, AZ & 37 \\
\hline HLCR & Little Colorado & Atomizer Falls and Colorado confluence & Coconino, AZ & 22 \\
\hline *HWWC & Colorado & Westwater Canyon & Grand, UT & 22 \\
\hline *HYAM & Yampa & Yampa Canyon & Moffat, CO & 8 \\
\hline Gila elegans & Hatchery stock & USFWS Hatchery at Dexter, NM & Chaves, NM & 11 \\
\hline
\end{tabular}

Site-abbreviated locality identifier for each species, Major drainage-River, Location — geographic site, County, State - per sampling site, and $N$-Number of samples excluding those that sequenced with sufficient coverage. An asterisk denotes sympatric localities
Cataract, Desolation, Grand, Westwater, and Yampa canyons (Fig. 1; USFWS 2011), all of which were sampled save Cataract Canyon. Westwater (HWWC) and Black Rocks (HBKR) were treated separately, despite their potential for connectivity (Francis et al. 2016). Due to its range-wide extirpation, samples of G. elegans were obtained from the Southwestern Native Aquatic Resources and Recovery Center, Dexter, NM (formerly the Dexter National Fish Hatchery). Our sampling of G. robusta encompassed its entire range, to include predefined MUs (=Management Units; Douglas and Douglas 2007) and represented wild populations, with the exception the Mancos River (RMCO), which was obtained from the Colorado Department of Wildlife Native Aquatic Species Restoration Facility. Gila robusta from the lower basin Bill Williams and Gila River drainages was not included, given its known polyphyly (Dowling and DeMarais 1993; Chafin et al. unpublished).

\section{Data collection}

Genomic DNA was extracted using either PureGene ${ }^{\circledR}$ or DNeasy ${ }^{\circledast}$ kits (Qiagen Inc.), with electrophoresis (2\%

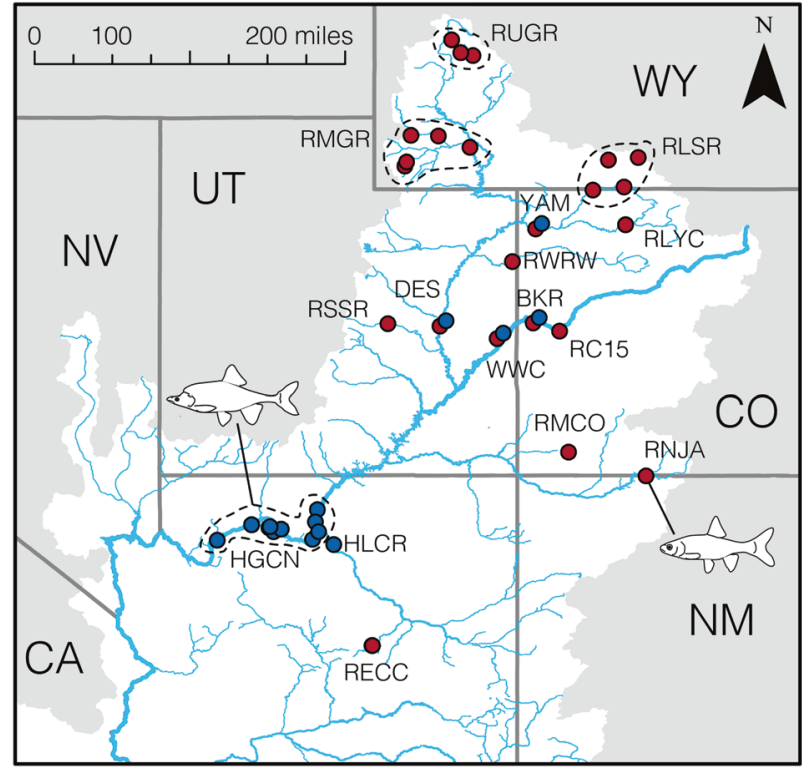

Fig. 1 Sampling localities for Gila cypha (blue) and G. robusta (red) within the Colorado River Basin, western North America. Locality codes are defined in Table 2. Sympatric locations (BKR, DES, WWC, and YAM) are slightly offset for visibility purposes. Inset cartoons the respective morphologies of each species 
agarose gel) confirming presence of sufficiently high molecular weight DNA. Our ddRAD library preparations were modified from previous protocols (Peterson et al. 2012). Restriction enzyme pairings and size-selection ranges were optimized using an in silico procedure (FRAGMATIC; Chafin et al. 2019). Samples were digested with MspI (5'CCGG-3') and PstI (5'-CTGCAG-3') following manufacturer's protocols (New England Biosciences). Fragments were then purified using Ampure XP beads (BeckmanCoulter Inc.) and concentrations standardized at $100 \mathrm{ng}$ per sample. Custom adapters containing in-line barcodes were ligated with T4 Ligase (New England Biosciences), pooled in sets of 48, and size-selected with the Pippin Prep (Sage Sciences) at $250-350 \mathrm{bp}$ prior to adjusting for adapter length (=gDNA length). We then utilized a 12-cycle PCR to extend adapters with indexed Tru-Seq primers and Phusion high-fidelity DNA polymerase (manufacturer protocols; New England Biosciences). Final libraries were visualized on the Agilent 2200 TapeStation fragment analyzer and pooled for $100 \mathrm{bp}$ read length single-end sequencing (Illumina HiSeq 2500; University of Wiscon$\sin$ /Madison).

\section{Assembly and filtering of genomic data}

Data assembly was performed using computing resources at the Arkansas High Performance Computing Center (AHPCC), and the XSEDE-funded cloud computing resource JetStream (co-managed by the Pervasive Technology Institute/Indiana University, and the Texas Advanced Computing Center/Austin).

Raw Illumina reads were demultiplexed and filtered using the PYRAD pipeline (Eaton 2014). Discarded reads exhibited $>1$ mismatch in the barcode sequence or $>5$ nucleotides with Phred quality $<20$. Loci were clustered de novo within and among samples using a distance threshold of $80 \%$. We then removed loci with: $>5$ ambiguous nucleotides; $>10$ heterozygous sites in the consensus sequence; $>2$ haplotypes per individual; $<20 \times$ and $>500 \times$ coverage per individual; $>70 \%$ heterozygosity per-site among individuals; or presence in $<50 \%$ of individuals. Individuals with $>50 \%$ missing data were also discarded. Scripts for post-assembly filtering and file conversion are available as open-source (github.com/tkchafin/scripts).

\section{Estimating population and individual ancestry}

Hypotheses of admixture and hybridization were based on genetic differentiation, as visualized using Discriminate Analysis of Principal Components (DAPC; R-package adegenet; Jombart 2008). Discriminant functions combine principal components (PCs) so as to maximally separate hypothesized groups. Importantly, sufficient PC axes must be retained so as to summarize the high-dimensional input, yet also avoid over-fitting. We accomplished this using the following cross-validation procedure: Stratified random sampling defined $80 \%$ of samples per population as a "training set," with the remaining $20 \%$ then classified. PC retention was optimized by minimizing root-mean-square error while maximizing classification success across analyses.

These results were contrasted with model-based assignment tests (STRUCture, Pritchard et al. 2000; ADMiXTure, Alexander and Novembre 2009). A shared assumption is that populations can be divided into $K$-clusters identified by permuting membership so as to minimize linkage disequilibrium and departure from Hardy-Weinberg expectations. Given excessive runtimes in STRUCTURE, we first applied ADMIXTURE to evaluate a broader range of models (i.e., $K=1-20$, using 20 replicates), followed by STRUCTURE on a reduced range $(K=1-10$, using 10 replicates with 500,000 MCMC iterations following a burn-in period of 200,000).

Model selection followed a cross-validation procedure in ADMIXTURE where assignment error was minimized by optimal choice of $K$, with results parsed using available pipelines (github.com/mussmann82/admixturePipeline). We used the delta $K$ method (Evanno et al. 2005) to define the proper model in STRUCTURE (CLUMPAK; Kopelman et al. 2015).

We identified putative admixed individuals using Bayesian genealogical assignment (NEWHYBRIDS, Anderson and Thompson 2002) that assessed the posterior probability of assignment to genealogical classes (e.g., $F_{1}, F_{2}$ ), as defined by expected genotype frequency distributions. This component is vital, in that mixed probability of assignment in STRUCTURE and ADMIXTURE can stem from weakly differentiated gene pools. The MCMC procedure in NEWHYBRIDS was run for 4,000,000 iterations following 1,000,000 burnin, using a panel of 200 loci containing the highest amongpopulation differentiation $\left(F_{\mathrm{ST}}\right)$ and lowest linkage disequilibrium $\left(r^{2}<0.2\right)$, as calculated in GENEPOPEDIT (Stanley et al. 2017). To ensure accuracy of this method as applied to our data, we performed a power analysis using the HYBRIDDETECTIVE workflow (Wringe et al. 2017). We first generated simulated multi-generational hybrids using $50 \%$ as a training dataset, and analyzed classification success across replicated simulations using the remaining $50 \%$ of samples as a validation set. To examine convergence, simulations were run across three replicates, each with three independent MCMC chains. Final runs were used to categorize individuals to genealogical class, using a posterior probability threshold of 0.90 .

\section{Spatial and genomic heterogeneity in introgression}

We tested for signatures of reproductive isolation by examining clinal patterns in locus-specific ancestry across 
hybrid genomes, using multinomial regression to predict genotypes as a function of genome-wide ancestry. Analyses were performed in the R-package introgress (Gompert and Alex Buerkle 2010). Putatively "pure" populations of $G$. robusta and G. cypha were diagnosed from results generated by NEWHYBRIDS. We first filtered loci to include those with allele frequencies that differed in the reference populations (as defined by $\delta>0.8$, where $\delta$ is the allele frequency differential at a given locus; Gregorius and Roberds 1986). We generated a null distribution by randomly reassigning genotypes across 1000 permutations, so as to test for deviations from neutral expectations. The significance of locus-specific clines (fit via multinomial regression) was then determined by computing a log-likelihood ratio of inferred clinal models versus the null model (at $P<0.001$ ).

To test for localized breakdown in reproductive barriers, we examined congruence of locus-specific introgression among sampling localities. We did so by deriving site-wise genomic clines within species, then subsequently contrasting the fit of site-wise regression models to the global pattern for each locus. This was accomplished by estimating probabilities of the observed genotypes for each site $\left(X_{i, j}\right.$ where $X=$ genotypic data over $i$ sites for each locus $j$ ) given the site-specific models $\left(M_{i, j}\right)$ versus the range-wide model $\left(M_{\text {global } j}\right)$. Concordance was reported as the log-likelihood ratio of $L\left(M_{\text {global }, j} \mid X_{i, j}\right)$ to $L\left(M_{i, j} \mid X_{i, j}\right)$ computed per locus (Gompert and Alex Buerkle 2010).

\section{Testing effects of anthropogenic pressures}

To test correlations between anthropogenic pressures on rates of hybridization, we parsed pressure indices per river reach for four dimensions of human impact from the global stream classifications of Grill et al. (2019). These were: (1) River fragmentation (=degree of fragmentation; DOF); (2) Flow regulation (=degree of regulation; DOR); (3) Sediment trapping (=SED); and (4) Water consumption (=USE), from the global stream classifications of Grill et al. (2019). We also tested predictive capacity of an integrated multicriterion connectivity status index $(=\mathrm{CSI})$, also from the free-flowing river assessments of Grill et al. (2019). Briefly, the DOF index (from 0 to 100) represents the flow disruption on a reach from dams, while also considering natural barriers such as waterfalls. The DOR index is derived from the relationship between storage volumes of reservoirs and annual river flows and is expressed as the percentage of total river flow that can be withheld in the reservoirs of a river reach. SED and USE quantify the potential sediment load trapped by dams, and the long-term average anthropogenic water consumption as a percentage of natural flow, respectively. The CSI index is a weighted average of these pressure indicators, while also considering road densities and degrees of urbanization [see Grill et al. (2019) for details regarding derivation of these indices and their underlying data sources].

We assigned pressure index values for all sites containing at least one hybrid (as classified using a 0.90 posterior probability threshold), and tested the predictive power of each pressure dimension on "genetic purity" (calculated via linear regression as the proportion of individuals per population assigned to either $P_{0}$ or $P_{1}$ ).

\section{Results}

A mean of 106,061 loci was assembled per sample ( $\sigma=$ $42,689)$. Following quality/depth filtering, and with mean coverage of $88 \times$, this yielded 16,001 per sample $(\sigma=6427)$. Loci were removed if absent in $<50 \%$ of individuals, with paralog filtering performed on the basis of allele count and excess heterozygosity. This resulted in 13,538 loci $(\mu=$ 10,$202 ; \sigma=3601$ ), and $1,257,356$ nucleotides. Putative orthologs contained $62,552 \mathrm{SNPs}$, of which 38,750 were parsimony-informative, corresponding to 4.9 and $3 \%$ of sampled nucleotides. We retained one SNP per locus, with a final dataset comprising 12,478 unlinked SNPs.

\section{Population structure}

Choice of $K$ varied by assignment test, with $K=8$ (ADMIXTURE; Fig. S1, S2, and $K=5$ (STRUCture; Fig. S2). We thus retained $K$-values from 5 to 8 .

The discriminant function axis with the greatest differentiation (DA1) primarily segregated $G$. robusta in the Little Colorado River (RECC) from the remaining $G$. robusta and G. cypha, with DA2 differentiating Upper Colorado G. robusta from G. cypha (Fig. 2a). Interestingly, DA3 (Fig. 2b) seemingly identified structure within $G$. cypha as well as potentially admixed populations of $G$. robusta. Both assignment tests (Fig. 3) differentiated RECC from conspecifics, with $G$. elegans also forming a discrete cluster in all cases. We interpret neither of these results as surprising, given the substantial anthropogenic (Glen Canyon dam) and natural (Little Colorado River Grand Falls) barriers separating the former from conspecifics, and the phylogenetic distinction of the former (Chafin et al. 2019). In addition, no signal of contemporary mixture of $G$. robusta or $G$. cypha with G. elegans was detected. STRUCTURE models with $K>8$ and ADMIXTURE $K>5$ showed similar restrictions in gene flow between Grand Canyon $G$. cypha versus upper basin sites. Desolation Canyon (HDES) showed the highest probability of assignment to an "upper basin" G. cypha cluster. Within G. robusta, a weak signal of differential assignment was apparent when Green River tributaries (RUGR and RMGR) were compared with the mainstem Colorado River, suggesting either reduced 


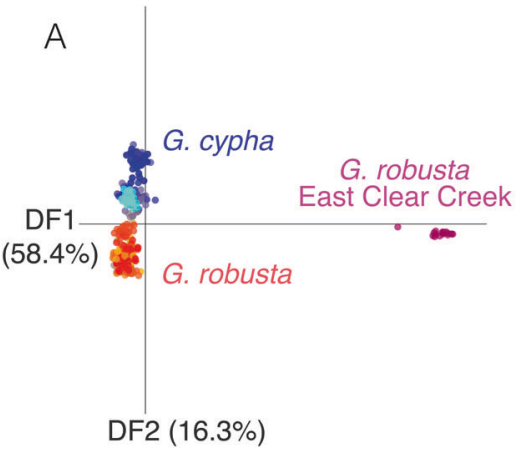

Fig. 2 Results of a discriminate analysis of principal components (DAPC) analysis depicting Gila robusta (red), G. cypha (blue), and their respective populations (as colored). a Discriminant function axes 1 and $2(=\mathrm{DF} 1 \times \mathrm{DF} 2)$ showing discrimination among both species; b axes 2 and $3(=\mathrm{DF} 2 \times \mathrm{DF} 3)$ reflecting the manner by which

STRUCTURE (Pritchard et al. 2000)
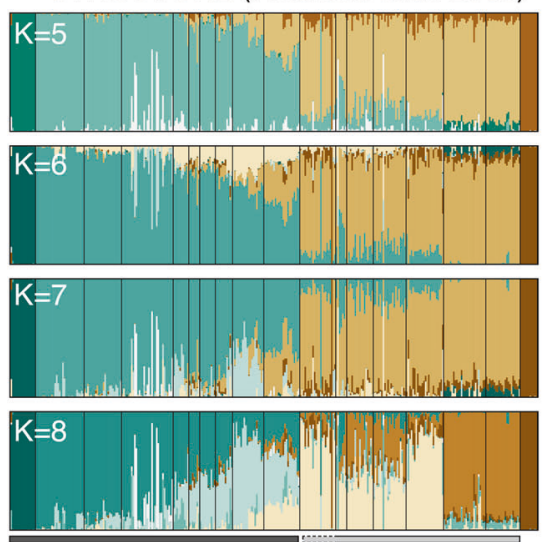

Roundtail chub Gila robusta

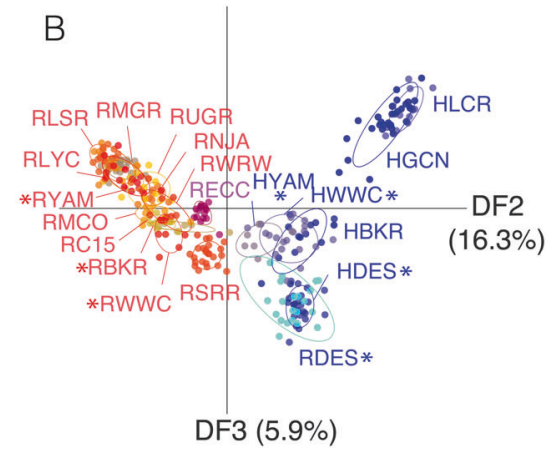

populations of each species (grouped within ellipses) are distributed in discriminant space. The relative percent variance captured by each discriminant function is presented in parentheses. Sample localities are defined in Table 1. An asterisk denotes sympatric localities

Fig. 3 Assignment results for ADMIXTURE and stRUCTURE analyses involving Gila robusta, G. cypha, and G, elegans. K-values range from stRUCTURE optimum $K=5$ (see Fig. S2) to ADMiXTuRe optimum $K=8$ (see Fig. S3). Locality abbreviations are as defined in Table 1 . An asterisk denotes sympatric localities

intraspecific gene flow, or an artifact of demographic processes.

DAPC and assignment tests each indicated potential hybridization among G. cypha and G. robusta, most prominently in regions of sympatry [i.e., Black Rocks (RBKR/ HBKR), Westwater (RWWC/HWWC), and Yampa (RYAM/ HYAM) canyons; Fig. 3]. Those G. robusta sites most "distant" in multivariate space (Fig. 2b) were also those which showed the least probability of interspecific assignment (Fig. 3). Signals of asymmetric introgression were apparent when sympatric localities were examined, with $G$. cypha generally having higher levels of heterospecific assignment.

One exception was RDES, where all specimens phenotypically identified as " $G$. robusta" were genetically indistinguishable from those designated as G. cypha. Misidentifications at time of capture is a likely cause, owing
ADMIXTURE (Alexander et al. 2009)
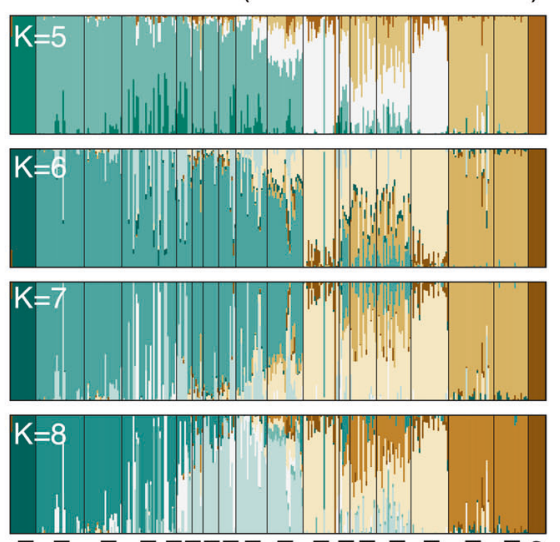

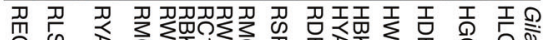

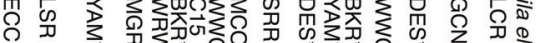

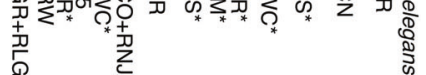

to the morphological intermediacy of Gila spp. at this site (i.e., McElroy and Douglas 1995).

Allopatric populations of G. robusta showed less interspecific ancestry, with the exception being the RSSR, where samples had 30-50\% assignment to G. cypha ancestry (Fig. 3), a pattern supported by the weak differentiation of RSSR in DAPC analyses. Allopatric G. robusta from RNJA also showed mixed probability of assignment to G. cypha, albeit with low probability and consistency.

\section{Hybrid detection and genealogical assignment}

Genealogical assignment in NEWHYBRIDS was used to parse STRUCTURE and ADMIXTURE results for contemporary hybridization. We first defined a prior probability of genetic purity for G. robusta as being the upper-most Little Snake 


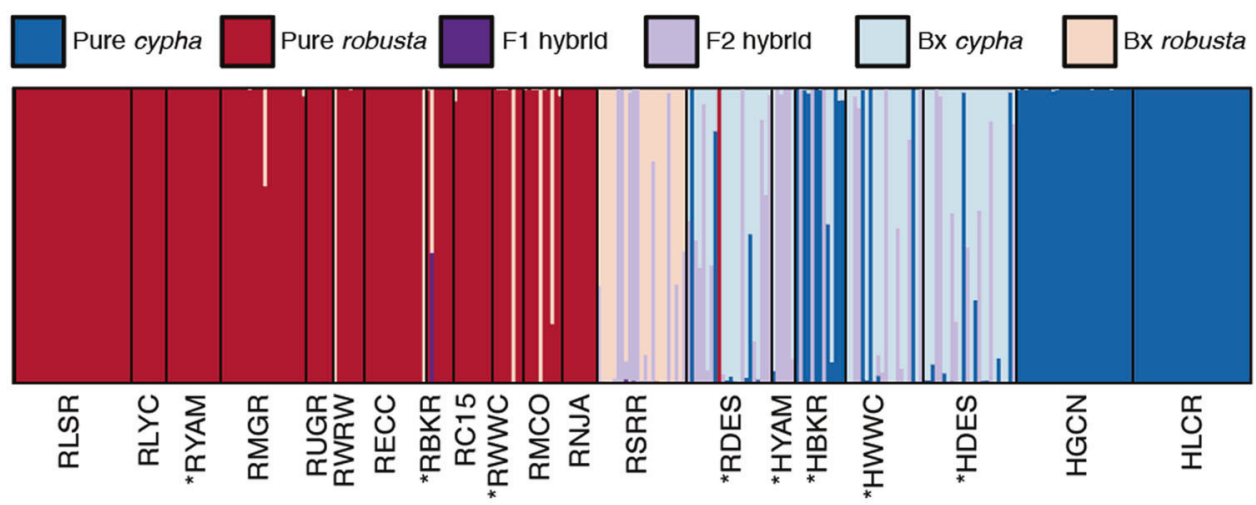

Fig. 4 Genealogical assignment for individual Gila robusta and $G$. cypha, as compiled from NEWHYBRIDS analysis. Individuals are represented by colored bars, with proportion of color indicating posterior probability of assignment per genealogical class. Prior "parental" allele frequencies for G. cypha were derived from the Little Colorado River (HLCR) and from the Little Snake River (RLSR) for G. robusta

River tributaries (RLSR), and for G. cypha as the Little Colorado River confluence in Grand Canyon (HLCR). Both were chosen based on STRUCTURE and ADMIXTURE results (Fig. 3), and additionally informed by prior studies of natural recruitment (Douglas and Douglas 2010; Kaeding and Zimmerman 1983). Because of the lack of any signal of interspecific admixture in G. elegans, they were omitted from these analyses.

Introgressive hybridization at sympatric locations was found to be asymmetric (Fig. 4). In cases of mixed assignment, individuals were classified as either "late-generation hybrid," or "of uncertain status" (Table 2). Gila robusta were largely classified as pure in both sympatric and allopatric sites, with a few exceptions (outlined below). Samples assigned to hybrid classes tended to be robustabackcrossed (6-12.5\%) or late-generation/uncertain (4.5-37.5\%). In contrast, G. cypha at sympatric localities had comparatively low purity (0-61\%), with most hybrids categorized as either $F_{2}$, cypha-backcrossed, or unclassifiable (Table 2). The genetic effects of hybridization are thus inferred as asymmetric, with a greater penetration of $G$. robusta alleles into G. cypha populations. RDES and HDES samples were mostly classified as either late-generation or unassignable. $F_{1}$ hybrids were notably absent at all localities, suggesting hybridization occurred over multiple generations and ongoing introgression (i.e., hybrids fertile and reproductively successful).

Both species showed little signal of hybridization at allopatric locations, but with notable exceptions being the RSRR and, to a lesser extent, RMCO. Nearly all RSSR samples were assigned with high probability as either $F_{2}$ or G. robusta-backcrossed hybrids, a pattern consistent across years (2009 versus 2017), and regardless of priors used. Samples from 2009 were mostly classified as $F_{2}(45 \%)$ or robusta-backcrosses (45\%). However, the greatest (alternative prior assignments had no significant affect; see Fig. S4 and S5). Colors are as follows: $\operatorname{Red}=$ pure G. robusta; Blue $=$ pure $G$. cypha; Purple $=F_{1}$ hybrid; Light purple $=F_{2}$ hybrid; Light blue $=$ cypha-backcrossed hybrid; Light red = robusta-backcrossed hybrid. An asterisk denotes sympatric localities

Table 2 Proportions of Gila robusta and G. cypha assigned genealogically at each sample site

\begin{tabular}{|c|c|c|c|c|c|c|c|}
\hline Site & $P_{0}$ & $P_{1}$ & $F_{1}$ & $F_{2}$ & $B_{0}$ & $B_{1}$ & $F_{\mathrm{N}}$ \\
\hline HLCR & - & 1.000 & - & - & - & - & - \\
\hline HGCN & - & 1.000 & - & - & - & - & - \\
\hline HDES & - & 0.083 & - & 0.083 & - & 0.542 & 0.292 \\
\hline HWWC & - & 0.150 & - & 0.200 & - & 0.550 & 0.100 \\
\hline HBKR & - & 0.615 & - & 0.231 & - & 0.077 & 0.077 \\
\hline HYAM & - & - & - & 0.667 & - & 0.333 & - \\
\hline RDES & 0.046 & 0.046 & - & 0.136 & - & 0.364 & 0.409 \\
\hline RSRR ('17) & - & - & - & 0.083 & 0.667 & - & 0.250 \\
\hline RSRR ('09) & - & - & - & 0.455 & 0.455 & - & 0.091 \\
\hline RNJA & 1.000 & - & - & - & - & - & - \\
\hline RMCO & 0.800 & - & - & - & 0.100 & - & 0.100 \\
\hline RWWC & 0.875 & - & - & - & 0.125 & - & 0.375 \\
\hline $\mathrm{RC} 15$ & 1.000 & - & - & - & - & - & - \\
\hline RBKR & 0.857 & - & - & - & - & - & 0.143 \\
\hline RECC & 0.938 & - & - & - & 0.063 & - & - \\
\hline RWRW & 0.875 & - & - & - & 0.125 & - & - \\
\hline RUGR & 1.000 & - & - & - & - & - & - \\
\hline RMGR & 0.955 & - & - & - & - & - & 0.045 \\
\hline RYAM & 1.000 & - & - & - & - & - & - \\
\hline RLYC & 1.000 & - & - & - & - & - & - \\
\hline RLSR & 1.000 & - & - & - & - & - & - \\
\hline
\end{tabular}

Site - abbreviated locality identifier for each species; $P_{0}$-Pure robusta; $P_{1}$-Pure cypha; $F_{1}$-First filial hybrid; $F_{2}$ - second filial hybrid; $B_{0}-G$. robusta-backcrossed hybrid; $B_{1}-G$. cypha-backcrossed hybrid; $F_{\mathrm{N}}$-late-generation or uncertain hybrid. Samples were assigned to a genealogical class per posterior probability $\geq 0.80$, as assessed using 250,000 post burn-in MCMC generations in NEWHYBRIDS.

proportion of 2017 samples were robusta-backcrosses $(67 \%)$ or late-generation hybrids $(25 \%)$, suggesting an 
increase of admixture over time (although increased sampling is needed to verify this trend; two-tailed Fisher's exact test $p=0.0967$; Table 2). The RMCO samples, composed of $20 \%$ hybrids (Table 2), were derived from hatchery stock, not a natural population. Thus, we cannot say if our results represent natural or accidental hybridization that coincided with, or was subsequent to, stock establishment.

\section{Genomic clines}

We also examined how introgression varied across significantly differentiated genomic SNPs and species-diagnostic markers. Here, we considered locus-specific ancestry as the probability of sampling a homozygous $G$. cypha genotype [i.e., $\mathrm{P}(\mathrm{AA})$ ] as a function of genome-wide ancestry, with the expectation that scant bias should occur if fitness is independent of hybrid ancestry. All loci exhibited clinal patterns that deviated significantly from neutral expectations $(p<$ 0.001, estimated via permutation; Fig. 5a). The majority displayed coincident sigmoidal relationships between genome-wide ancestry (hybrid index; $h$ ) and locus-specific ancestry $(\phi)$. The dominant sigmoidal pattern is suggestive of a deficiency in interspecific heterozygosity, presumably reflecting heterozygote disadvantage (Fitzpatrick 2013). Notably, some locus-specific clines deviated from this trend (Fig. 5a), suggesting that underdominance is not ubiquitous. For example, many loci show alternative cline shapes suggestive of either over- or under-representation of parental genotypes in hybrids, suggestive of a selective advantage in these or linked genomic regions. However, lacking a suitable genomic reference, the phenotypic implications of these alternative cline forms are not explored herein.

We also examined the observed genotypes at each locus, given expectations from the range-wide model and sitespecific regression models. These were reported as a loglikelihood ratio per locus and within each sampling locality (Fig. 5b). We found the "fit" of the range-wide clinal models was rather variable, although with the majority of loci showing little deviation. One notable exception was RSSR, where an exceptionally flattened distribution of the locus-specific log-likelihood ratios was apparent. This in turn suggested that the global expectation was a poor predictor of within-population genotypes. Thus, while most loci reflected patterns consistent with selection against hybrids, the same cannot be said for the RSSR population. It also displayed a strong signal of interspecific admixture in the Bayesian and ML assignment tests (Fig. 3), and variable assignment to $>2$ nd generation hybrid classes in NEWHYBRIDS (Fig. 4), as well as greater intermediacy in multivariate genotypic clustering (Fig. 2). Several other sites also showed a "flattened" distribution of clinal fit among loci (e.g., HWWC, HBKR, HDES, RDES, RUGR, RMCO; see Fig. 5b). This could be a response to elevated introgression and a relative breakdown of heterozygote disadvantage in the sympatric localities (HWWC, HBKR, HDES, RDES), especially where previous analyses indicated admixture (Figs. 2-4), or as an artifact of reduced sampling (RUGR, RMCO).
Fig. 5 Genomic cline analyses for populations of Gila robusta and G. cypha, presented as: a Per-locus clinal relationships for 50 SNPs with $\delta>0.8$ (all significantly non-neutral at $\alpha=$ 0.001) compared with the neutral expectation (shaded gray region); b Log-likelihood ratio distribution of site-wise perlocus clines compared to the global pattern, where higher loglikelihood ratio indicates greater discordance; c Per-locus incongruence in genomic clines in the Gila robusta samples from the San Rafael River, partitioned by year (2009 versus 2017).

Locality codes for populations of each species are defined in Table 1
A
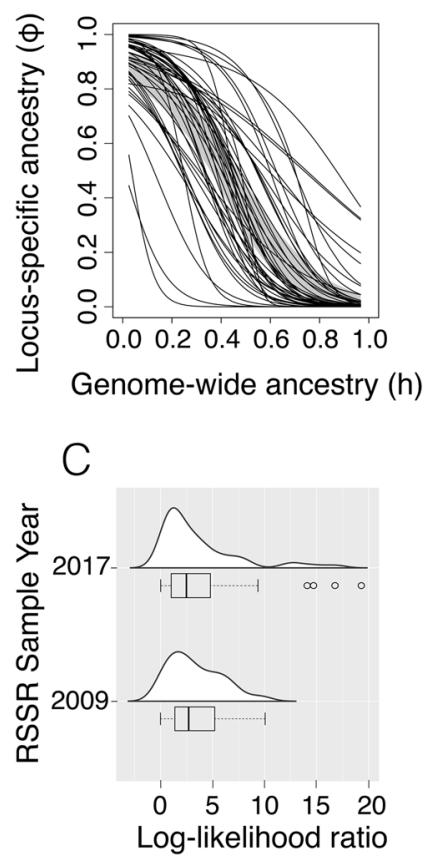

B

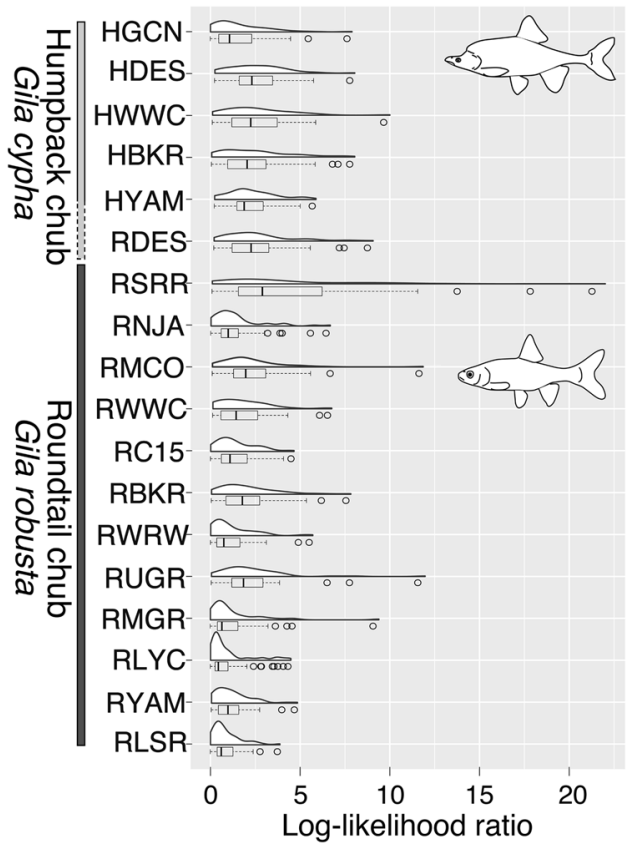


Although not possible for other localities, our temporal sampling for RSSR allowed us to further explore this discrepancy across different time periods: $2009(N=11)$ and $2017(N=12)$. We then fitted locus-specific clines among years (Fig. 5c) and compared those with range-wide expectations (Fig. 5b). We found little qualitative change in the overall distribution, save for four outliers in 2017, suggesting further breakdown of clinal expectations over time. Even though we cannot evaluate this trend rangewide, we suggest that further study examine the persistence versus breakdown of genetic purity by using a consistent genetic assay as a part of ongoing monitoring efforts.

\section{Testing dimensions of anthropogenic pressure}

Among sites showing varying levels of hybridization $(N=$ 10; Table 2), only the consumptive water use (=USE) was significantly corelated with a decline in genetic purity $\left(r^{2}=\right.$ 0.444 ; adjusted $r^{2}=0.375 ; p=0.035$; see Fig. S5). The connectivity status index (CSI) showed a weak but nonsignificant positive relationship (i.e., increased connectivity $=$ increased genetic purity; $r^{2}=0.02$; adjusted $r^{2}=-0.103$; $p=0.7)$. However, we caution that sample sizes were notably low $(N=10)$ after sites were reduced to those containing hybrids and which could be assigned pressure indices (see Fig. S6 for reach assignments), thus urge that these results be interpreted accordingly.

\section{Discussion}

We found strong evidence for contemporary hybridization among $G$. cypha and $G$. robusta extending beyond their regions of sympatry. These results refine rather than conflict with previous studies employing "legacy" genetic markers (Douglas and Douglas 2007; Dowling and DeMarais 1993; Gerber et al. 2001), and complement contemporary work (Bohn et al. 2019). In addition, these results broaden our understanding of each species and their evolutionary histories, as well as the trajectory of their ongoing evolutionary change in the face of extensive anthropogenic modifications.

\section{Species boundaries and reproductive isolation in Gila}

Our survey of the nuclear genome suggested that contemporary hybridization between our study species is occurring where sympatric, as interpreted from several lines of evidence: the coincidence and shape of our genomic clines; the pervasive signal of genealogical assignment to early-generation hybrid classes; and signatures of selection antagonistic to interspecific heterozygous genotypes.
We interpret this hybridization as following historical isolation, particularly given the coexistence of study species since at least the mid-Pliocene (Uyeno and Miller 1965; Spencer et al. 2008). In addition, past studies have shown sustained morphological divergence displayed in sympatry (Douglas et al. 1989; McElroy and Douglas 1995), although we note that contemporary evaluations are conspicuously absent. This suggests that genetic exchange is ongoing despite, rather than in the absence of, reproductive isolation.

Dowling and DeMarais (1993) suggested that hybridization between $G$. cypha and $G$. robusta may have contributed to the evolutionary persistence of each species by providing necessary adaptive genetic variation so as to withstand environmental fluctuations. We concur, and further note that this exchange is ongoing, with a substantial risk that contemporary habitat change will outpace the rate at which introgressed alleles are selectively "filtered." If so, then continued habitat alteration could lead to a scenario in which genetic/demographic swamping contributes to local extirpations, or to eventual genetic homogenization of one species by the other (Todesco et al. 2016). This pattern is particularly evident in the asymmetric levels of introgression into G. cypha, a species of particular concern given its fragmentary distribution and reduced densities within the upper Colorado River Basin (e.g., Badame 2008; Francis et al. 2016; USFWS 2017).

To consider the plausibility of such a scenario in which environmental change leads to the dissolution of a species boundary, we must first consider how this boundary is itself structured. We do so by considering results of our genetic data within the context of those derived from speciesspecific morphology and life history. Several morphological evaluations have demonstrated that morphological distinctions among species can be blurred in sympatry (Douglas and Douglas 2007; Douglas et al. 2001; McElroy and Douglas 1995), although we note a need for such evaluations to be revisited, particularly given the contemporary timescale of hybridization as documented herein. This is likely the result of secondary admixture, rather than a prolonged (i.e., primary) divergence that lead to only weaklydifferentiated species. Pliocene fossils demonstrate that morphological divergence of $G$. robusta and $G$. cypha predates major geomorphic and tectonic events that could have triggered secondary contact. For example, the Upper Colorado River was segregated from the contemporary lower basin prior to the mid-Pliocene (McKee et al. 1967), with the uplifting of the Colorado Plateau diverting its flow into one or more Colorado Plateau lakes (Spencer et al. 2008). Flows were subsequently diverted by headwater erosion though the Grand Canyon, forming the modern course of the river. Fossil evidence implies that ecological divergence occurred during, or prior to this time, and was sufficient in strength to generate both morphological forms 
(Uyeno and Miller 1965). This suggests the existence of ecological conditions that reflect those to which the species are now adapted. In addition, numerous perturbations [i.e., tectonism, extreme drought (Meko et al. 2007)] also occurred during the interval between divergence and present, yet both species not only persisted but did so with some semblance of morphological continuity. Given this, one must again assume that an extant blurring of species boundaries is, at least in part, a contemporary occurrence. To test this hypothesis, we considered the ecological dimensions underlying adaptive differentiation in these species.

\section{Reproductive barriers in Gila}

Phenotypic and ecological specializations of each species provide potential insights into the mechanisms promoting assortative mating. Gila cypha displays phenotypic characteristics interpreted as adaptations to the torrential flows of canyon-bound reaches (McElroy and Douglas 1995; Miller 1946; Valdez and Clemmer 1982). These include a prominent nuchal hump, dorsoventrally flattened head, embedded scales, terete body shape, and a very narrow caudal peduncle that terminates in a caudal fin with a high aspect ratio, indicative of a hydrodynamic shape and powerful propulsion. Its current distribution also reflects association with this type of habitat.

In contrast, G. robusta has a comparatively more generalized phenotype, characterized by a deeper and less streamlined body with non-imbedded scales and larger, more falcate fins (Miller 1946). It is found in the upper tributaries of larger rivers (Vanicek and Kramer 1969) with moderate flows. It fails to maintain position within the current when subjected to the extreme flows associated with G. cypha, and instead becomes benthic so as to avoid being swept away (Moran et al. 2018). This suggests a natural history diametrically opposed to that of $G$. cypha, where dynamic flow regimes clearly predominate. Accordingly, radiotelemetric studies verified habitat preferences for each species, with G. cypha seldom straying from the deep eddies and turbulent flows of canyon-bound reaches (Douglas and Marsh 1996; Gerig et al. 2014; Kaeding et al. 1990). These observations underscore the role that functional morphology plays with regards to species boundaries, in that intermediate morphologies would be maladaptive in either habitat.

However, barriers that sustain reproductive isolation are unclear, in that both species are broadcast-spawners (Johnston and Page 1992), with a temporal overlap in spawning period (Kaeding et al. 1990). The latter is likely a consequence of shared environmental cues triggering reproduction, namely seasonal changes in flow rate and temperature, with spatial segregation driven by subsequent alterations in microhabitat and substrate preference (Douglas and Douglas 2000; Minckley 1996). Widespread movements by $G$. robusta during the spawning season contrast with the relative localized focus found in $G$. cypha (Kaeding et al. 1990), and again reinforce the restricted habitat requirements of the latter. In addition, there is a stronger "homing" component in the microhabitat preferences of G. cypha (Valdez and Clemmer 1982). These ecological differences, combined with overall higher abundance of G. robusta in most areas (e.g., Francis et al. 2016) likely contribute to the observed asymmetric introgression between the two species (Edelaar et al. 2008). Intraspecific recognition as a mate-choice mechanism is also an observed behavior that promotes reproductive isolation. Despite congruent reproductive condition and the presence of suitable substrate in a brood stock tank, natural spawning did not occur between $G$. robusta $\times G$. elegans and G. elegans $\times$ G. cypha (Hamman 1981).

Thus, we contend that reproductive isolation in $G$. robusta and G. cypha is driven by extrinsic factors, with pre-mating isolation primarily in the form of microhabitat selection and post-mating isolation driven by functional morphological differences. Our data point to selection against hybrids, which may be reflective of either their relatively poor performance in the environment, or to a diminished success in mating. However, we noted a possible breakdown of this expectation at some localities when genomic clines were fitted to within-site patterns. The RSRR, for example, is one such exception. Fortney (2015) quantified anthropogenic changes in this river over the last 100 years, with the channel being extensively canalized and diverted, and flows diminished by $83 \%$ due to water withdrawals. These manipulations yielded a narrower, relatively deeper channel that stands in sharp contrast to a historically wider and slower river whose flow regime was governed by geomorphology and dominated by flooding. Anthropogenic alterations apparently provided an opportunity for adaptive hybridization (e.g., Taylor et al. 2005), a hypothesis consistent with the exclusive presence of late-generation hybrids in the RSSR population (Fig. 4). Under this scenario, selective advantage would similarly drive outlier loci and the reduced-fit seen in our clinal models (Fig. 5). The origin of G. cypha alleles in this population is unclear, although they may possible be derived from a remnant population in the upper reaches (e.g., Black Box Gorge; P. Badame, personal communication).

An examination of the degree to which anthropogenic pressures drive basin-wide hybridization point to a role for consumptive water use in driving a decline in overall genetic purity. Consumptive water usage, and the impact of the associated infrastructures (such as diversions and reservoirs), are often implicated as detrimental to freshwater fish diversity (e.g., Xenopoulos et al. 2005). Insofar as river 
discharge is one dimension of ecological heterogeneity, and given the trend of decreasing species richness as flow declines (Oberdorff et al. 1995), we posit that a coincidental relationship is rather extreme in the Colorado River when anthropogenic manipulations and extensive hybridization are contrasted. Yet, a test of this hypothesis is difficult without further experimental work (i.e., leveraging hatchery-produced interspecific hybrids to test for viability in varying habitats, represented within a series of mesocosms). While increased sampling is also necessary, it would be difficult given that we have already sampled 4 of the 5 extant $G$. cypha populations.

\section{Modified environments and genetic swamping}

Grabenstein and Taylor (2018) defined mechanisms that drive anthropogenically-mediated hybridization in coexisting species: (1) Interspecific contact promoted by habitat homogenization or altered phenology; (2) Disruption of mate selection/ choice; and (3) Habitat alteration, such that hybrid genotypes are favored (Anderson 1948). All three are plausible for Gila, with the "hybrid swarm" of RSSR an extreme case. Asymmetric hybridization was implicated in all extant sympatric G. cypha populations, save the Cataract Canyon aggregate not evaluated in this study. The latter reflects a more "robusta-like" morphology (McElroy et al. 1997), with low population numbers and a slower growth rate relative to other extant populations (Badame 2008). Taken together, these suggest an elevated risk for genetic or demographic swamping in Cataract Canyon G. cypha (Todesco et al. 2016), and lend urgency to their inclusion in future genetic surveys.

Such a scenario may also be invoked for G. cypha in the Yampa River (HYAM), recognized even prior to our sampling as being of reduced and declining numbers (Tyus 1998). The ubiquity of highly-admixed genomes in our sampling (from 1999 to 2001), coupled with the absence of genetically pure individuals in more recent surveys (USFWS 2017), suggest the potential for local extirpation. Given the prevalence of asymmetric hybridization in other sympatric G. cypha, it is possible that genetic swamping may have also played a role in the decline of the HYAM population (although we cannot test that hypothesis). Of note, a more recent genetic survey of HYAM found a further breakdown of genetic purity, with most individuals being composed of either pure G. robusta or robustabackrosses (Bohn et al. 2019). Similarly, recent surveys have also documented diminished catch ratios for G. cypha at other sympatric localities (Fig. 4; Francis et al. 2016; USFWS 2017). Thus, an elevated risk of genetic swamping appears as a strong potential for all G. cypha populations sympatric with $G$. robusta.

\section{Genetic swamping and Allee effects}

The capacity for populations to track changing conditions is constrained not only by standing genetic variation but also complex demographic processes that feed back to reproductive fitness (Kokko et al. 2017). As the effective population size $\left(N_{\mathrm{e}}\right)$ of a population decreases, so also do beneficial variants, primarily due to reduced efficacy of selection relative to genetic drift and associated inbreeding depression (i.e., Allee effects; Kramer et al. 2009). This in turn can induce a negative feedback that drives local extirpation (Polechová and Barton 2015). Using a similar logic, we posit that maladaptive introgression within diminishing populations could also synergistically trigger a "runaway" process of genetic swamping (Fig. S7).

In this conceptual model, demographically-driven Allee effects weakens purifying selection against maladaptive introgressed alleles, whereas their continued influx further reduces fitness via outbreeding depression. In this way, maladaptive gene flow can continually depreciate $N_{\mathrm{e}}$ and effectively promote an "extinction vortex" (Gilpin and Soulé 1986), and we posit this mechanism may contribute to the decline of those G. cypha populations sympatric with G. robusta. Although some signal of selection against heterospecific alleles was apparent, another manifestation of shrinking $N_{\mathrm{e}}$ is the expansion of genomic linkage disequilibrium (Nachman 2002). As a result, purifying selection can actually be counterproductive, wherein beneficial genetic variation is lost via selection against linked regions (Nachman and Payseur 2012).

Under this paradigm, the risk of swamping in G. cypha is elevated by the numerous factors that increase the relative impact of genetic drift. These are: reduced population sizes in extant populations (Douglas and Marsh 1996; Tyus 1998); a fragmented distribution (Fagan 2002); and a "slow" life history (i.e., long generation time and extended lifespans; Olden et al. 2008), and higher vulnerability to regulated and reduced flows given its habitat preference of turbulent rivers (as above). The hybrid swarm in the San Rafael (RSRR), and the suspected genetic swamping of $G$. cypha in the Yampa River (HYAM) are potential harbingers of this erosion. Genetic integrity may be preserved in the short term by cultivating "pure" progeny via hatchery production, so as to potentially extend existing pure populations, although a propogation program risks further reducing $N_{\mathrm{e}}$ (Allendorf et al. 2001). The development of pure stock for $G$. robusta should be relatively easy, whereas upper basin G. cypha are more problematic in that they display various levels of hybridization (i.e., Figs. 3 and 4). In this regard, we echo the "producer's gambit" philosophy (McElroy et al. 1997) where hybrid populations fall under an expanded conservation paradigm when genetic purity 
cannot otherwise be maintained (Lind-Riehl et al. 2016). Given apparent ecological non-equivalency of hybrids, we suggest that habitat restoration is the only long-term means to resurrect genetic purity in these populations (Wayne and Shaffer 2016). Here, restoration reestablishes adaptive gradients favoring specialist phenotypes, even so far as to drive their reemergence from hybridized swarms (Gilman and Behm 2019), as has been seen in European whitefish following eutrophication-driven hybridization (Jacobs et al. 2019). Thus, restoration efforts may be more effectively targeted to areas of already reduced purity, with continued genetic monitoring as a necessary assessment tool (e.g., Bohn et al. 2019).

\section{Conclusions}

A reduced-representation assay of nuclear genomes in $G$. robusta and G. cypha provided evidence of asymmetrical hybridization that is range-wide and spatially heterogeneous (Figs. 3 and 4). We interpreted this as reflecting secondary contact, particularly given the pervasive selection we found with regard to genomic clines operating against interspecific heterozygotes (Fig. 5), although we do not exclude the potential for historically limited introgression. Although we lacked appropriate sampling to adequately test for temporal changes in hybridization rates, we did observe the expansion of a hybrid swarm in the RSSR over an eight-year period, as well as high levels of asymmetric hybridization in all sympatric populations of G. cypha (Table 2). This underscores the potential for genetic/demographic swamping by $G$. robusta, as well as exacerbating the extirpation risk for extant populations of G. cypha. We argue that conservation plans for G. cypha must consider this possibility. We also suspect the species boundary for G. cypha is largely maintained by extrinsic factors (i.e., lower fitness of hybrid phenotypes and differential microhabitat preferences). As such, further habitat degradation and homogenization may lead to complete genetic erosion, either by contravening habitat selection for pure individuals, or by promoting modified anthropogenic riverscapes that serve as habitat for novel hybrid lineages/swarms. The scenario playing out in Gila emphasizes a philosophical dilemma that conservation policy must confront: is hybridization antagonistic to the conservation of biodiversity or is it instead a natural adaptive mechanism employed routinely by species in their evolutionary struggle to persist.

\section{Data accessibility}

All raw sequence files are accessioned in the NCBI GenBank Sequence Read Archive (SRA) under BioProject
PRJNA558355. Relevant curated (i.e., assembled and filtered) datasets are archived on Dryad (https://doi.org/10. 5061/dryad.d3q3220). Codes and custom scripts developed in support of this work are also available as open-source under the GNU Public License via GitHub: github.com/ tkchafin (and as cited in-text).

Acknowledgements This research was conducted in partial fulfillment by TKC of the Ph.D. degree in Biological Sciences at the University of Arkansas, as enabled by a Distinguished Doctoral Fellowship (DDF) award. Numerous agencies and organizations contributed field expertise, sampling, permit authorization, funding, and/or valuable comments: Arizona Game and Fish Department, Colorado Division of Wildlife, Jicarilla Apache Game and Fish, Nevada Department of Wildlife, United States Fish and Wildlife Service, Utah Department of Natural Resources, Utah Division of Wildlife, and the Wyoming Game and Fish Department. Particular thanks are extended to J. Alves, M. Anderson, R. Anderson, P. Badame, K. Bestgen, M. Breen, K. Breidinger, S. Bryan, P. Cavalli, B. DeMarais, T. Dowling, R. Fridell, K. Gelwicks, K. Hilwig, M. Hudson, D. Keller, J. Logan, C. McAda, S. Meisuer, T. Modde, K. Morgan, F. Pfeifer, S. Ross, R. Timmons, P. Unmack, D. Weedman, K. Wilson, and E. Woodhouse (with apologies to anyone inadvertently overlooked). Additional sampling was completed by MED and MRD under permits provided by Arizona Game and Fish Department, Dinosaur National Monument, Grand Canyon National Park/Glen Canyon National Recreation Area, The Hualapai Tribe, The Navajo Nation, Nevada Division of Wildlife, U.S. Fish and Wildlife, and Wyoming Department of Game and Fish. Sampling procedures were approved under Arizona State University Animal Care and Use Committee (ASU IACUC) permit 98-456R and Colorado State University Animal Care and Use Committee (CSU IACUC) permit 01-036A-01. Travel in the Grand Canyon was conducted under auspices of a Grand Canyon National Park river use permit. We are also indebted to students, postdoctorals, and faculty who have promoted our research: A. Alverson, W. Anthonysamy, M. Bangs, M. Davis, L. James, S. Mussmann, J. Pummill, A. Tucker. Funding was provided by several generous endowments from the University of Arkansas: The Bruker Professorship in Life Sciences (MRD), and the Twenty-First Century Chair in Global Change Biology (MED). Additional analytical resources were provided by the Arkansas Economic Development Commission (Arkansas Settlement Proceeds Act of 2000) and the AHPCC, and from an NSFXSEDE Research Allocation (TG-BIO160065) to access the Jetstream cloud. The findings and conclusions in this article are those of the authors and do not necessarily represent the views of the contributing individuals, organizations, or funding agencies.

Author contributions TKC, MED, and MRD conceptualized and designed the research. MED and MRD contributed sampling and coordination of agency efforts. TKC performed molecular work and analyses. TKC and BTM wrote software and codes to analyze data in support of this research. All authors contributed to writing the manuscript and approve of the final submission.

\section{Compliance with ethical standards}

Conflict of interest The authors declare that they have no conflict of interest.

Publisher's note: Springer Nature remains neutral with regard to jurisdictional claims in published maps and institutional affiliations. 


\section{References}

Alexander DH, Novembre J (2009) Fast model-based estimation of ancestry in unrelated individuals. Genome Res 19:1655-1664

Allendorf FW, Leary RF, Spruell P, Wenburg JK (2001) The problems with hybrids: setting conservation guidelines. Trends Ecol Evol 16:613-622

Anderson E (1948) Hybridization of the habitat. Evolution 2:1-9

Anderson EC, Thompson EA (2002) A model-based method for identifying species hybrids using multilocus data. Genetics 160:1217-1229

Arnold ML, Martin NH (2010) Hybrid fitness across time and habitats. Trends Ecol Evol 25:530-536

Badame P V (2008). Population estimates for humpback chub (Gila cypha) in cataract canyon, Colorado River, Utah, 2003-2005. Final Report to Utah Division of Wildlife Resources Upper Colorado River Endangered Fish Recovery Program Project \#22L

Bangs MR, Douglas MR, Mussmann SM, Douglas ME (2018) Unraveling historical introgression and resolving phylogenetic discord within Catostomus (Osteichthys: Catostomidae). BMC Evol Biol 18:1-16

Bohn S, Mussmann SM, Wilson WD. 2019. Genetic evaluation of upper Colorado River basin Gila cypha. Rep to US Fish and Wildlife Service; U.S. Department of the Interior. $62 p$

Buerkle CA, Wolf DE, Loren H (2003). The origin and extinction of species through hybridization. In: Brigham CA, Schwartz MW (eds) Population viability in plants: conservation, management, and modelling of rare plants, vol 165, pp 117-141

Cayan DR, Das T, Pierce DW, Barnett TP, Tyree M, Gershunov A (2010) Future dryness in the southwest US and the hydrology of the early 21st century drought. Proc Natl Acad Sci 107:21271-21276

Chafin TK, Douglas MR, Bangs MR, Mussmann SM, Douglas ME (2019). Taxonomic uncertainty and phylogenomics: rescuing a contentious species complex from the anomaly zone. bioRxiv. https://doi.org/10.1101/692509

DeMarais BD, Dowling TE, Douglas ME, Minckley WL, Marsh PC (1992) Origin of Gila seminuda (Teleostei: Cyprinidae) through introgressive hybridization: implications for evolution and conservation. Proc Natl Acad Sci 89:2747-2751

Dittrich-Reed DR, Fitzpatrick BM (2013) Transgressive hybrids as hopeful monsters. Evol Biol 40:310-315

Douglas M, Marsh P (1996) Population estimates/population movements of Gila cypha, an endangered cyprinid fish in the Grand Canyon region of Arizona. Copeia 1:15-28

Douglas ME, Douglas MR, Lynch JM, McElroy DM (2001) Use of geometric morphometrics to differentiate Gila (Cyprinidae) within the Upper Colorado River Basin. Copeia 2001:389-400

Douglas ME, Miller RR, Minckley WL (1998) Multivariate discrimination of Colorado plateau Gila spp.: the 'art of seeing well' revisited. Trans Am Fish Soc 127:163-173

Douglas ME, Minckley WL, Tyus HM (1989) Qualitative characters, identification of Colorado River chubs (CyprinidaeL Genus Gila) and the 'art of seeing well'. Copeia 1989:653-662

Douglas MR, Douglas ME (2000) Late season reproduction by bigriver Catostomidae in Grand Canyon (Arizona). Copeia 2000:238-244

Douglas MR, Douglas ME (2007) Genetic structure of humpback chub Gila cypha and roundtail chub G. robusta in the Colorado River ecosystem. Report to Grand Canyon Monitoring and Research Center, US Geological Survey 99p.

Douglas MR, Douglas ME (2010) Molecular approaches to stream fish ecology. Am Fisheries Soc Symp 73:157-195

Dowling TE, DeMarais BD (1993) Evolutionary significance of introgressive hybridization in cyprinid fishes. Nature 362:444-446
Dowling TE, Secor CL (1997) The role of hybridization and introgression in the diversification of animals. Annu Rev Ecol Syst 28:593-619

Eaton DAR (2014) PyRAD: assembly of de novo RADseq loci for phylogenetic analyses. Bioinformatics 30:1844-1849

Edelaar P, Siepielski AM, Clobert J (2008) Matching habitat choice causes directed gene flow: A neglected dimension in evolution and ecology. Evolution 62:2462-2472

Evanno G, Regnaut S, Goudet J (2005) Detecting the number of clusters of individuals using the software STRUCTURE: a simulation study. Mol Ecol 14:2611-2620

Fagan WF (2002) Connectivity, fragmentation, and extinction risk in dendritic metapopulations. Ecology 83:3243-3249

Fitzpatrick BM (2013) Alternative forms for genomic clines. Ecol Evol 3:1951-1966

Fitzpatrick BM, Ryan ME, Johnson JR, Corush J, Carter ET (2015) Hybridization and the species problem in conservation. Curr Zool 61:206-216

Fortney ST (2015). A century of geomorphic change of the San Rafael River and implications for river rehabilitation. Masters Thesis, Utah State University, Logan

Francis TA, Bestgen KR, White GC (2016). Population status of Humpback chub, Gila cypha, and catch indices and population structure of sympatric Roundtail chub, Gila robusta, in Black Rocks, Colorado River, Colorado, 1998-2012. Larval Fish Laboratory Contribution 199. Final Report from the U.S. Fish and Wildlife Service to the Upper Colorado River Endangered Fish Recovery Program, Project Number 131. Grand Junction Colorado.

Gerber AS, Tibbets CA, Dowling TE (2001) The role of introgressive hybridization in the evolution of the Gila robusta complex (Teleostei: Cyprinidae). Evolution 55:2028-2039

Gerig B, Dodrill MJ, Pine WE (2014) Habitat selection and movement of adult Humpback chub in the Colorado River in Grand Canyon, Arizona, during an experimental steady flow release. North Am J Fish Manag 34:39-48

Gilman RT, Behm JE (2019) Hybridization, species collapse, and species reemergence after disturbance to premating mechanisms of reproductive isolation. Evolution 65(9):2592-605

Gilpin M, Soulé ME (1986) Minimum viable populations: the processes of species extinction. In: Soule ME, Orians GH (eds) Conservation biology: The science of scarcity and diversity, Sinauer and Associates Inc., pp. 13-34

Gompert Z, Alex Buerkle C (2010) Introgress: a software package for mapping components of isolation in hybrids. Mol Ecol Resour 10:378-384

Grabenstein KC, Taylor SA (2018) Breaking barriers: causes, consequences, and experimental utility of human-mediated hybridization. Trends Ecol Evol 33:198-212

Gregorius HR, Roberds JH (1986) Measurement of genetical differentiation among subpopulations. Theor Appl Genet 71(6):826-34

Grill G, Lehner B, Thieme M, Geenen B, Tickner D, Antonelli F, Babu S, Borrelli P, Cheng L, Crochetiere H, Ehalt Macedo H, Filgueiras R, Goichot M, Higgins J, Hogan Z, Lip B, McClain BE, Meng J, Mulligan M, Nilsson C, Olden JD, Opperman JJ, Petry P, Reidy Liermann C, Saenz L, Salinas-Rodriguez S, Schelle P, Schmitt RJP, Snider J, Tan F, Tockner K, Valdujo PH, van Soesbergen A, Zarfl C (2019) Mapping the world's freeflowing rivers. Nature 569(7755):215-221

Hamilton JA, Miller JM (2016) Adaptive introgression as a resource for management and genetic conservation in a changing climate. Conserv Biol 30:33-41

Hamman RL (1981) Hybridization of three species of chub in a hatchery. Prog Fish-Cult 43:131-134

Hoffmann AA, Sgrò CM (2011) Climate change and evolutionary adaptation. Nature 470:479-485 
Hopken MW, Douglas MR, Douglas ME (2013) Stream hierarchy defines riverscape genetics of a North American desert fish. Mol Ecol 22:956-971

Hubbs CL (1955) Hybridization between fish species in nature. Syst Zool 4:1-20

Jacobs A, Carruthers M, Eckmann R, Yohannes E, Adams CE, Behrmann-Godel J, Elmer KR (2019) Rapid niche expansion by selection on functional genomic variation after ecosystem recovery. Nat Ecol Evolut. 3:77-86

Johnston CE, Page LM (1992). The evolution of complex reproductive strategies in North American minnows (Cyprinidae). In: Mayden RL (ed) Systematics, historical ecology, and North American freshwater fishes, Stanford University Press, pp 601-621

Jombart T (2008) Adegenet: A R package for the multivariate analysis of genetic markers. Bioinformatics 24:1403-1405

Kaeding LR, Burdick BD, Schrader PA, McAda CW (1990) Temporal and spatial relations between the spawning of humpback chub and roundtail chub in the upper Colorado River. Trans Am Fish Soc 119:134-144

Kaeding LR, Zimmerman MA (1983) Life history and ecology of the humpback chub in the Little Colorado and Colorado rivers of the Grand Canyon. Trans Am Fish Soc 112:577-594

Kearns AM, Restani M, Szabo I, Schrøder-Nielsen A, Kim JA, Richardson HM et al. (2018) Genomic evidence of speciation reversal in ravens. Nat Commun 9:906

Klein EK, Lagache-Navarro L, Petit RJ (2017) Demographic and spatial determinants of hybridization rate. J Ecol 105:29-38

Klonner G, Dullinger I, Wessely J, Bossdorf O, Carboni M, Dawson $\mathrm{W}$ et al. (2017) Will climate change increase hybridization risk between potential plant invaders and their congeners in Europe? Divers Distrib 23:934-943

Kokko H, Chaturvedi A, Croll D, Fischer MC, Guillaume F, Karrenberg S, Kerr B, Rolshausen G, Stapley J (2017) Can Evolution Supply What Ecology Demands? Trends Ecol Evol 32(3):187-197

Kopelman NM, Mayzel J, Jakobsson M, Rosenberg NA, Mayrose I (2015) Clumpak: a program for identifying clustering modes and packaging population structure inferences across K. Mol Ecol Resour 15:1179-1191

Kramer AM, Dennis B, Liebhold AM, Drake JM (2009) The evidence for Allee effects. Popul Ecol 51:341-354

Lind-Riehl JF, Mayer AL, Wellstead AM, Gailing O (2016) Hybridization, agency discretion, and implementation of the U.S. Endagered Species Act. Conserv Biol 30:1288-1296. https://doi. org/10.1111/cobi.12747

Lindsey HA, Gallie J, Taylor S, Kerr B (2013) Evolutionary rescue from extinction is contingent on a lower rate of environmental change. Nature 494:463-467

Mallet J, Besansky N, Hahn MW (2016) How reticulated are species? BioEssays 38:140-149

Mandeville EG, Parchman TL, Thompson KG, Compton RI, Gelwicks KR, Song SJ et al. (2017) Inconsistent reproductive isolation revealed by interactions between Catostomus fish species. Evol Lett $1: 1-14$

McElroy DM, Douglas ME (1995) Patterns of morphological variation among endangered populations of Gila robusta and Gila cypha (Teleostei: Cyprinidae) in the Upper Colorado River Basin. Copeia 1995:636-649

McElroy DM, Shoemaker JA, Douglas ME (1997) Discriminating Gila robusta and Gila cypha: risk assessment and the endangered species act. Ecol Appl 7:958-967

McKee ED, Wislon RF, Breed WJ, Breed CS (1967). Evolution of the Colorado River in Arizona-an hypothesis developed at the symposium on cenozoic geology of the colorado plateau in Arizona, August 1964. Museum of Northern Arizona Bulletin
Meier JI, Marques DA, Mwaiko S, Wagner CE, Excoffier L, Seehausen O (2017) Ancient hybridization fuels rapid cichlid fish adaptive radiations. Nat Commun 8:1-11

Meko DM, Woodhouse CA, Baisan CA, Knight T, Lucas JJ, Hughes MK et al. (2007) Medieval drought in the upper Colorado River Basin. Geophys Res Lett 34:1-5

Miller RR (1946) Gila cypha, a remarkable new species of cyprinid fish from the Colorado River in Grand Canyon, Arizona. J Washing Acad Sci 36:409-415

Minckley CO (1996). Observations on the biology of the Humpback chub in the Colorado River Basin 1980-1990. Doctoral dissertation Thesis. Northern Arizona University, Flagstaff

Moran CJ, Gerry SP, Neill MWO, Rzucidlo CL, Gibb AC (2018) Behavioral and physiological adaptations to high-flow velocities in chubs (Gila spp.) native to Southwestern USA. J Exp Biol 221: pii: jeb158972

Nachman MW (2002) Variation in recombination rate across the genome: evidence and implications. Curr Opin Genet Dev 12:657-663

Nachman MW, Payseur BA (2012) Recombination rate variation and speciation: theoretical predictions and empirical results from rabbits and mice. Philos Trans R Soc Lond B Biol Sci 367 (1587):409-421

Oberdorff T, Guégan JF, Oberdorff BI, Hugueny J-F, Guégan J-F (1995) Global scale patterns of fish species richness in rivers. Ecography 18:345-352

Olden JD, Poff NL, Bestgen KR (2008) Trait synergisms and the rarity, extirpation, and extinction risk of desert fishes. Ecology $89: 847-856$

Orr HA, Unckless RL (2014) The population genetics of evolutionary rescue. PLoS Genet 10:1-9

Pease JB, Haak DC, Hahn MW, Moyle LC (2016) Phylogenomics reveals three sources of adaptive variation during a rapid radiation. PLoS Biol 14:1-24

Pecl GT, Araújo MB, Bell JD, Blanchard J, Bonebrake TC, Chen IC et al. (2017) Biodiversity redistribution under climate change: Impacts on ecosystems and human well-being. Science 355:pii: eaai9214

Peterson BK, Weber JN, Kay EH, Fisher HS, Hoekstra HE (2012) Double digest RADseq: an inexpensive method for de novo SNP discovery and genotyping in model and non-model species. PLoS One 7:e37135

Polechová J, Barton NH (2015) Limits to adaptation along environmental gradients. Proc Natl Acad Sci 112:6401-6406

Portz DE, Tyus HM (2004) Fish humps in two Colorado River fishes: a morphological response to cyprinid predation? Environ Biol Fishes 71:233-245

Pritchard JK, Stephens M, Donnelly P (2000) Inference of population structure using multilocus genotype data. Genetics 155:945-959

Ryan SF, Deines JM, Scriber JM, Pfrender ME, Jones SE, Emrich SJ, Hellmann JJ (2018) Climate-mediated hybrid zone movement revealed with genomics, museum collection, and simulation modeling. Proc Natl Acad Sci 115(10):E2284-E2291

Schumer M, Rosenthal GG, Andolfatto P (2018) What do we mean when we talk about hybrid speciation? Heredity 120:379-382

Seehausen O, Takimoto G, Roy D, Jokela J (2008) Speciation reversal and biodiversity dynamics with hybridization in changing environments. Mol Ecol 17:30-44

Smith GR, Miller RR, Sable WD (1979). Species relationships among fishes of the genus Gila in the upper Colorado River drainage. In: Proceedings of the First Conference on Scientific Research in National Parks, Vol. II, pp 613-623

Spencer JE, Smith GR, Dowling TE (2008) Middle to late Cenozoic geology, hydrography, and fish evolution in the American Southwest. Geol Soc Am 439:279-99

Stanley RRE, Jeffery NW, Wringe BF, DiBacco C, Bradbury IR (2017). Genepopedit: a simple and flexible tool for 
manipulating multilocus molecular data in R. Mol Ecol Res 17 (1): $12-18$

Taylor EB, Boughman JW, Groenenboom M, Sniatynski M, Schluter D, Gow JL (2005) Speciation in reverse: morphological and genetic evidence of the collapse of a three-spined stickleback (Gasterosteus aculeatus) species pair. Mol Ecol 15 (2):343-55

Thomaz AT, Christie MR, Knowles LL (2016) The architecture of river networks can drive the evolutionary dynamics of aquatic populations. Evolution 70:731-739

Todesco M, Pascual MA, Owens GL, Ostevik KL, Moyers BT, Hübner S et al. (2016) Hybridization and extinction. Evol Appl 9:892-908

Tyus HM (1998) Early records of the endangered fish Gila cypha Miller from the Yampa River of Colorado with notes on its decline. Copeia 1998:190-193

USFWS (2011). 5-year review: humpback chub (Gila cypha) summary and evaluation. USFWS

USFWS (2017) Species status assessment for the humpback chub (Gila cypha). U.S. Fish and Wildlife Service Mountain-Prairie Region (6), Denver, CO

Uyeno T, Miller RR (1963) Summary of late Cenozoic freshwater fish records for North America. Occas Pap Mus Zool Univ Mich 631:1-34

Uyeno T, Miller RR (1965). Middle Pliocene cyprinid fishes from the Bidahochi formation. Copeia 1965(1):28-41
Valdez RA, Clemmer GH (1982) Life history and prospects for recovery of the humpback and bonytail chub. In: Fishes of the Upper Colorado River System: Present and Future, pp. 109-119

Valdez RA, Holden PB, Hardy TB (1990) Habitat suitability index curves for Humpback chub of the Upper Colorado River Basin. Rivers 1:31-42

Vanicek CD, Kramer RH (1969) Life history of the Colorado Squawfish, Ptychocheilus lucius, and the Colorado chub, Gila robusta, in the Green River in Dinosaur National Monument, 1964-1966. Trans Am Fish Soc 98(2):193-208

vonHoldt BM, Brzeski KE, Wilcove DS, Rutledge LY (2018) Redefining the role of admixture and genomics in species conservation. Conversat Lett 11:1-6

Wayne RK, Shaffer HB (2016) Hybridization and endangered species protection in the molecular era. Mol Ecol 25:2680-2689

Wringe BF, Stanley RRE, Jeffery NW, Anderson EC, Bradbury IR (2017) hybriddetective: a workflow and package to facilitate the detection of hybridization using genomic data in r. Mol Ecol Resour 17:e275-e284

Xenopoulos MA, Lodge DA, Alcamo J, Marker M, Schulze K, van Vuuren DP (2005) Scenarios of freshwater fish extinctions from climate change and water withdrawal. Glob Chang Biol 11:1557-1564 